\title{
Antonio Candido em Assis e depois .
}

\author{
Rodrigo Martins Ramassote ${ }^{2}$
}

\section{Resumo}

Este artigo aborda a passagem de Antonio Candido pela Faculdade de Filosofia, Ciências e Letras de Assis do Instituto Isolado de Ensino Superior do Governo do Estado de São Paulo (atualmente integrado à Unesp), ocorrida entre 1958 e 1960, destacando a importância do período em sua trajetória intelectual e acadèmica. Apesar de breve, e pouco comentada, a transferência para Assis foi decisiva na: a) passagem profissional do campo da sociologia para a área de literatura; b) na estruturação de uma plataforma de ensino que será retomada na direção do curso de Teoria Literária e Literatura Comparada na FFLC/USP; c) no estímulo para a elaboração dos primeiros escritos da fase madura de sua produção crítica, marcada pela preocupação com o processo de redução estrutural.

\section{Palavras-chave}

Antonio Candido; história intelectual; Faculdade de Filosofia, Ciências e Letras de Assis.

Recebido em 10 de abril de 2009

Aprovado em 17 de dezembro de 2009

1 Este artigo baseia-se, em grande parte, em questões discutidas no primeiro capítulo da minha dissertação de mestrado, intitulada Aformação dos desconfiados: Antonio Candido e a crítica literária acadêmica (1961 - 1978), defendida no Departamento de Antropologia Social do IFCH/Unicamp sob a orientação da Profa. Dra. Heloisa Pontes, a quem agradeço pela leitura e incentivo constante. O título faz referência tanto ao escrito de homenagem Antonio Candido antes e depois de Assis (1992), redigido por António Lázaro de Almeida (In: D'INCAO, Maria Ângela e SCARABÔTOLO, Eloísa Faria. (Org.). Dentro do texto, dentro da vida: ensaios sobre Antonio Candido. São Paulo: Companhia das Letras, 1992. p. 54-57), quanto, sobretudo, ao ensaio Sergio Buarque de Holanda em Berlim e depois, no qual Candido assinala a influência duradoura da breve estada, entre 1933 e 1934 , do futuro historiador paulista na capital alemã como correspondente d'O Jornal: "Esse ano e meio foi tão importante em sua vida intelectual que muitos pensam que ficou mais tempo" (CANDIDO, Antonio. Sergio Buarque de Holanda em Berlim e depois. In:

Vários Escritos. 3. ed. rev. e ampl, São Paulo: Editora Duas Cidades, 1995. p. 323.).

2 Doutorando em Antropologia Social pela Unicamp. Desde agosto de 2006 exerce o cargo de antropólogo pelo Instituto do Patrimônio Artístico Nacional (IPHAN).

E-mail: ramassote@hotmail.com 


\title{
Antonio Candido in Assis and his afterwards
}

\author{
Rodrigo Martins Ramassote
}

\begin{abstract}
This article explores A. Candido's passage through Faculdade de Filosofia, Ciências e Letras de Assis, part of the Instituto Isolado de Ensino Superior do Governo do Estado de São Paulo (now Unesp), ocurred between 1958 and 1960. It points out to the importance and the meaning of this period for his intellectual and academic trajectory. Although this period was brief and not fully commented, his transference to a newly created college in São Paulo hinterland was important as: a) his professional passage from sociology to literature; b) his teaching platform which will become the basis for his Literary Theory and Comparative Literature course at the FFCL/USP; c) an stimulation for his essays of the mature phase, all of them concerned with the process of structural reduction.
\end{abstract}

Keywords

Antonio Candido; Intellectual History; Faculdade de Filosofia, Ciências e Letras de Assis. 


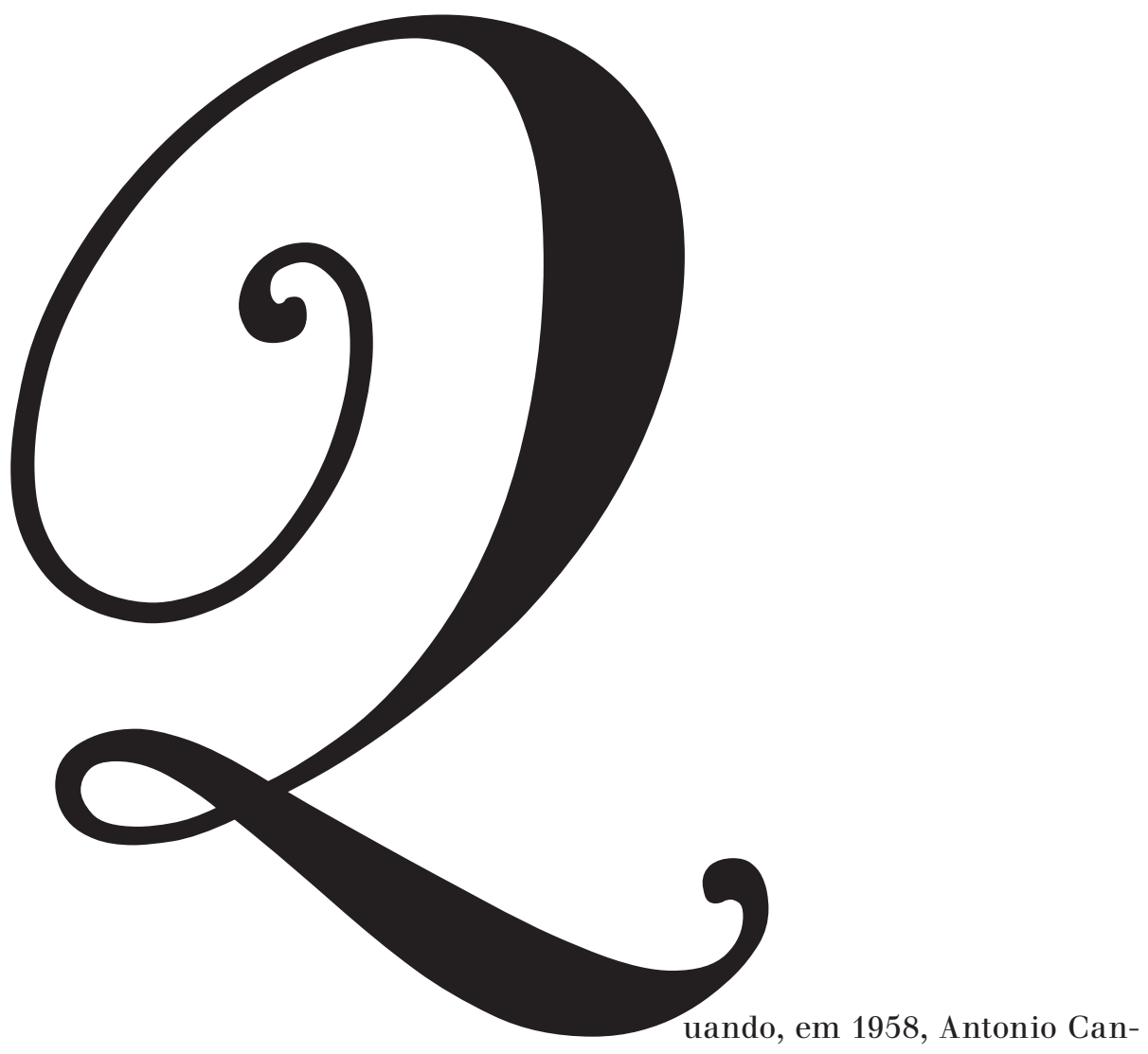

dido decidiu desligar-se da cadeira de Sociologia II da Faculdade de Filosofia, Ciências e Letras (FFCL) da Universidade de São Paulo (USP) - em cujo âmbito exercera atividades de docência e pesquisa durante dezesseis anos - para assumir o cargo de professor de literatura brasileira no curso de Letras da recém-inaugurada Faculdade de Filosofia, Ciências e Letras de Assis, do Instituto Isolado de Ensino Superior do Governo do Estado de São Paulo (atualmente integrado à Unesp), tal atitude causou surpresa e certa consternação até mesmo entre seus amigos mais próximos. Quem relata é o próprio Candido, num registro eloquente da estranheza provocada pela situação. Diz ele que ao receber a notícia na Europa, Paulo Emílio Salles Gomes, crítico e estudioso de cinema e companheiro intelectual desde os idos da publicação da revista Clima, teria exclamado: "Que coisa extraordinária! Antonio Candido vai poder afinal se dedicar à literatura, e ensinando literatura brasileira naquela paisagem da Umbria! Que coisa extraordinária! (risos). Ele imaginou que seria uma faculdade italiana e me viu em Assis, na Úmbria”. Quando foi alertado de que se tratava na verdade de uma pacata cidadezinha situada 
no interior paulista, o crítico de cinema teria bradado: "Assis da Sorocabana? Então o Antonio é uma besta!”’ .

Mal-entendido à parte, a resposta de Paulo Emílio dá notícia da radicalidade da decisão tomada por A. Candido. Invertendo a lógica do modelo de carreira profissional "ascendente, que, quando parte da 'periferia', almeja chegar ao 'centro' do sistema profissional", a mudança da prestigiosa FFCL/USP para uma incipiente unidade de ensino do interior do estado, aparenta ser, à primeira vista, tão-somente um breve e insignificante desvio de rota na trajetória acadêmica de A. Candido, destituído de maior interesse e ocorrido imediatamente antes de assumir o curso de Teoria Literária e Literatura Comparada na USP. Curta, porém decisiva, a passagem de dois anos em meio de A. Candido pelo curso de Letras de Assis, entre o segundo semestre de 1958 e o final de 1960, demarcou uma inflexão em sua trajetória profissional, sendo responsável, acima de tudo, por viabilizar o primeiro contato direto e regular com a docência e pesquisa acadêmica na área de Letras. Neste artigo pretendo demonstrar que, ao contrário da visão corrente, que tende a minimizar a importância do período em questão, as implicações e o significado da passagem por Assis não foram ainda devidamente aquilatados, repercutindo em vários níveis de significado: a) no plano da consolidação da identidade profissional como professor e pesquisador no campo das Letras, enquanto um ritual de passagem, na acepção clássica da expressão; b) como plataforma de ensino que irá nortear a constituição do curso de Teoria Literária e Literatura Comparada (TLLC), idealizado e coordenado por ele, a partir de dezembro de 1960, na FFCL/USP; c) no tocante programa crítico de A. Candido, marco inaugural das diretrizes da fase madura de sua trajetória intelectual.

\section{Movimento e parada}

Sob a coordenação geral de Antonio Soares Amora ${ }^{5}$, professor titular da Cadeira de Literatura Portuguesa do curso de Letras da

3 CANDIDO, Antonio. Entrevista concedida a Décio de Almeida Prado, publicada em: MARTINS, Marília e ABRANTES, Paulo (Org.). Três Antônios e um Jobim. Rio de Janeiro: Relume/Dumará, 2001. p. 113.

4 PONTES, Heloisa. Destinos mistos: os críticos do Grupo Clima em São Paulo. São Paulo: Companhia das Letras, 1998. p. 179.

5 Segundo Oliveira, em importante estudo, a nomeação de Amora para o cargo, ocorrida em 22 de agosto de 1957, promulgada pelo Governador Jânio Quadros, deve-se a três fatores: a) por influência da esposa de José Santilli Sobrinho, mais importante político da região de Assis e principal animador da criação da Faculdade, Profa. 
Universidade de São Paulo, começaram a ser realizadas, a partir de 1957, as primeiras providências necessárias para a implantação institucional da Faculdade de Filosofia, Ciências e Letras em Assis, SP. Sua criação, ocorrida em sessão solene no dia 16 de agosto de 1958, deu-se no contexto de expansão do ensino superior público para o interior do estado, tendo como objetivo atender a demanda estudantil por vagas no ensino superior bem como ampliar o contingente de professores formados para o exercício do magistério secundário.

Com o desafio de implantar numa pequena cidade distante da capital uma instituição universitária de alto nível de excelência acadêmica, foi iniciado no mesmo ano o "trabalho preparatório do corpo docente por meio de reuniões prévias, ainda em São Paulo, a fim de que a equipe se entrosasse na medida do possível e definisse seu espírito"6. Em catorze reuniões ocorridas entre janeiro e julho de 1958, realizadas, em caráter provisório, no salão do então Instituto de Estudos Portugueses, foram acordados pelo grupo inicial de professores os primeiros passos para a montagem dos pré-requisitos institucionais essenciais para a implantação da nascente Faculdade: como principal ideário de ensino, “o princípio de observância estrita do tempo integral, a disposição de prestar assistência efetiva aos estudantes, a ideia de um ritmo de trabalho comportando distribuição equilibrada do tempo entre ensino e pesquisa"; como proposta de atividades práticas, o "plano da biblioteca-piloto, a iniciativa da Revista de letras, previsão de uma série de monografias", bem como o planejamento dos programas de curso e a realização de um curso preparatório para selecionar os alunos ingressantes.

Para compor a equipe de professores, Amora procurou convocar, em sua grande maioria, profissionais em início de carreira, mas já com contribuições científicas significativas, oriundos tanto dos quadros da FFLC/USP, quanto do exterior, sobretudo provenientes de Portugal, dada

\footnotetext{
Maria Aparecida de Campos Brando Santilli, que conhecia o trabalho de Amora; b) ao prestígio de Amora como professor, bem como o fato de ele ter organizado na década de $195^{\circ}$ o Instituto de Estudos Portugueses; c) às relações pessoais de Amora com Jânio Quadros, que se conheceram quando ambos lecionaram Língua Portuguesa no ensino secundário. Cf. OLIVEIRA, Fábio Ruela de. A Faculdade de Assis e a formação da Unesp (1958-1964). Versão revista de dissertação de mestrado defendida originalmente no Programa de Pós-Graduação de "História e Sociedade" da Faculdade de Ciências e Letras da Unesp/Campus de Assis/SP, 2008. 188p.

6 CANDIDO, Antonio. Discurso. In: . Brigada ligeira e outros escritos. São Paulo: Ed. da UNESP, 1992. p. $25^{\circ}$.

7 Idem, ibidem, p. 250 .
} 
a relação de Amora com o país ${ }^{8}$. Informado por colega comum do interesse de A. Candido em afastar-se das funções de professor assistente da Cadeira de Sociologia II para lecionar na área de Letras, Amora decidiu convidá-lo para integrar o grupo, oferecendo-lhe a vaga disponível na cadeira de Literatura Brasileira. Sem hesitar, A. Candido aceitou a indicação e começou a participar das reuniões periódicas do grupo de professores que estava projetando a estrutura acadêmica e administrativa da nascente instituição: "Minha decisão foi imediata. Era hora de mudar e Assis foi fundamental na minha vida". Como compreender tamanha reviravolta? Vejamos, em detalhe, alguns aspectos de ordem acadêmica e intelectual que impulsionaram a decisão de A. Candido.

Intelectual cada vez mais renomado, prestes a completar quarenta anos de idade, Antonio Candido encontrava-se em fins de 1957, quando recebeu o convite de Antonio Soares Amora, num momento delicado de sua carreira profissional acadêmica. Dividido, desde 1942, quando ingressou como professor assistente da cadeira de Sociologia II na FFCL/ USP, entre a docência e pesquisa universitária no campo da sociologia e a publicação de artigos na grande imprensa e de livros na área que o consagrou, A. Candido encontrou, a partir da segunda metade da década de 1950, cada vez menos espaço para dar continuidade às duas frentes de interesse em que alternava sua produção intelectual. Nesta altura, já não era mais aceitável levar adiante o destino misto tão característico de seu grupo universitário, tal como fora possível durante os primeiros anos de sua atividade profissional.

Como se sabe, A. Candido ingressou em 1939 no curso de Ciências Sociais da recém-fundada Faculdade de Filosofia, Ciências e Letras da Universidade de São Paulo, instado pela curiosidade em compreender a chamada "realidade brasileira", num decênio de grande agitação social e política, dentro e fora do país. Ao longo da graduação (1939 - 1941), A. Candido recebeu sólida formação científica pela mão de mestres estrangeiros contratados para renovar os padrões e critérios intelectuais de docência e pesquisa universitária, rompendo com o modelo praticado

8 Neste ponto o projeto também se aproxima, conforme repara Oliveira, da Faculdade de Filosofia, Ciências e Letras da USP, que recorreu, inicialmente, à contratação de professores estrangeiros para ocupar parte das cadeiras dos cursos criados a partir de 1934. OLIVEIRA, Fábio Ruela de. op. cit.

9 CANDIDO, Antonio. Entrevista concedida a Décio de Almeida Prado. op. cit., p. 113. 
nos demais centros tradicionais de ensino superior pelo país, no qual imperava a mentalidade jurídica encarnada na figura do bacharel.

Já durante os primeiros anos da graduação, nas aulas do curso de filosofia ministradas por Jean Maügué, A. Candido estreitou o contato com um conjunto de jovens estudantes - entre eles, Décio de Almeida Prado, Gilda Rocha, Ruy Coelho, Paulo Emílio Salles Gomes, Lourival Gomes Machado - que viriam a formar o célebre Grupo Clima. Unidos pela convivência estreita no interior da faculdade, pela origem social semelhante e pelo conjunto de referências intelectuais compartilhadas, entre eles surgiu a ideia de produzir uma revista cultural dedicada às artes em geral. Editada entre 1941 e 1944 (com três momentos de interrupção), a revista Clima, em seus dezesseis números, de acordo com Pontes,

ocupa um lugar muito preciso na trajetória de seus editores e colaboradores mais próximos. Por meio desse experimento cultural de juventude, com forte conotação de marco inaugural, conseguiram um tríplice feito: fixaram os contornos da plataforma intelectual e política da geração e, em particular, do grupo de que faziam parte; lançaram as bases para a construção de uma dicção autoral própria; viabilizaram o início de suas carreiras como críticos profissionais. ${ }^{10}$

Na seção fixa dedicada à crítica literária, A. Candido publicou os primeiros artigos na área que o consagraria, os quais garantiram-lhe de imediato o reconhecimento público e permitiram-lhe intensificar relações com escritores, editores, artistas e demais integrantes do cenário cultural paulista - em especial com os intelectuais ligados ao movimento modernista.

Concluída a graduação em Ciências Sociais, A. Candido foi convidado, pelo regente Fernando Azevedo, a tornar-se professor assistente da cadeira de Sociologia II, passando a lecionar sociologia em disciplinas introdutórias dos cursos de Pedagogia e Filosofia, auxiliar nas demais atividades de ensino e, por iniciativa pessoal, logo encampada pelo segundo assistente, Florestan Fernandes, realizar colóquios semanais com os alunos a fim de minorar as carências formativas dos ingressantes no curso.

Paralelamente à vida acadêmica, com a visibilidade alcançada pela participação na revista Clima, A. Candido foi convidado para efetivar-se como crítico literário titular na grande imprensa paulista, a princípio, no jornal Folha da manhã (1943 - 1945), e, logo depois, no Correio de São

1 PONTES, Heloisa. Destinos mistos: os críticos do Grupo Clima em São Paulo. op.cit., p. 112. 
Paulo (1945 - 1947), passando a produzir semanalmente um rodapé em que acompanhava o movimento da produção literária do período. Em quatro anos de atividade ininterrupta, A. Candido deu mostras de sua capacidade analítica e juízo crítico apurados, reconhecendo de imediato o talento e valor literário de autores estreantes como Clarice Lispector, João Cabral de Mello Neto e João Guimarães Rosa.

Ambicionando uma possível transferência em definitivo para o setor de Letras, A. Candido decidiu participar de concurso público aberto em 1944 para provimento da cadeira de Literatura Brasileira do curso de Letras da FFCL/USP, o qual permitia, de acordo com a legislação em vigor, que pudessem se candidatar ao cargo todos os portadores de diploma de ensino superior em qualquer área de especialidade, conquanto que o candidato apresentasse um trabalho acadêmico original e fosse avaliado através de "prova de títulos; prova escrita com ponto sorteado na hora; aula com ponto sorteado 24 horas antes"11.

Para concorrer à vaga, A. Candido defendeu como trabalho, após alguma indecisão inicial ${ }^{12}$, estudo monográfico sobre o jurista e crítico sergipano Sílvio Romero, autor que lhe é bastante familiar desde a adolescência. Redigida entre junho de 1944 e fevereiro de 1945, a tese $O$ método crítico de Sílvio Romero elucidava os princípios teórico-metodológicos da proposta crítica propugnada por Romero, salientando, de um lado, a sua contribuição ao "ambiente cultural" brasileiro do final do século XIX (ao ter ressaltado os aspectos sócio-culturais envolvidos na criação literária, nos quais se destacavam a "teoria da mestiçagem" e a "teoria da representatividade") e, de outro, as limitações e impasses decorrentes dos preceitos científicos das análises e interpretações romerianas, os quais acabaram por distorcer-lhe as apreciações estéticas. Fixando sua própria concepção e modelo de pesquisa em "ciência da literatura", A. Candido defendia que "haja o que houver e seja como for, em literatura a importância maior deve caber à obra. A literatura é um conjunto de obras, não de fatores, nem de autores"13.

Numa disputa acirrada - passível, inclusive, de ser questionada à época, já que no cômputo geral A. Candido obteve a maior nota ${ }^{14}$-, que terminou com a aprovação, empatados, de A. Candido e Mário de

11 GALVÃO, Walnice Nogueira. A aula. In: D'INCAO, Maria Ângela e SCARABÔTOLO, Eloísa Faria (Org.). op.cit., p. 180.

12 Cf. CANDIDO, Antonio. Mário e concurso. In: Recortes. São Paulo: Companhia das Letras, 1993 .

13 Idem. O método crítico de Sílvio Romero. São Paulo: Edusp, 1988. p. 103.

14. Cf. Idem. Mário e concurso. op. cit., e PONTES, Heloisa. Entrevista com Antonio Candido. Revista Brasileira de Ciências Sociais, v. 16, $\mathrm{n}^{0}$ 47, 2001. 
Souza Lima, o conselho universitário decidiu em favor do último, que já regia, em caráter interino, a cadeira em disputa. Em compensação, por ter sido aprovado, A. Candido recebeu conforme os critérios estipulados pelo concurso, o título de livre-docente em Literatura Brasileira, o que lhe credenciaria seguir, caso desejasse, carreira no curso de Letras. No mesmo ano, publicou Brigada ligeira (1945), reunião de rodapés publicados na Folha da manhã, com especial ênfase em artigos dedicados à prosa de ficção.

Movido, por um lado, pela frustração com o resultado obtido no concurso e, por outro, premido pela instauração do regime de trabalho integral para os assistentes da FFCL/USP, requisitando a vivência plena de uma ambiência acadêmica, fato que oferecia condições menos favoráveis para a continuidade de atividades em que se dividia, A. Candido decidiu suspender, ainda que provisoriamente, os rodapés literários. Redefinindo suas prioridades profissionais, no ano de 1947, iniciava uma nova fase em sua trajetória, na qual passava a investir mais seriamente na produção de conhecimento na área de sua formação acadêmica inicial, até o momento deixada em segundo plano em favor dos compromissos com a atividade literária. Surgia então o primeiro artigo publicado no campo da sociologia, Opiniões e classes sociais no Tietê (1947), a que se seguiram onze artigos, publicados entre 1947 e 1956, num ritmo contínuo de um por ano, “com exceção de 1950, quando não publicou, e 1954 e 1955, quando foram duas publicações" ${ }^{\text {"15 }}$.

Nesse mesmo período, A. Candido deu início aos primeiros passos de sua pesquisa de doutorado em ciências sociais. Inscrito desde 1943 na Especialização em Sociologia, sob a orientação de Fernando de Azevedo, e frequentando como disciplinas subsidiárias os cursos de Roger Bastide e Emílio Willems - cujos Seminários de Leitura, em 1943 e 1944, tiveram especial impacto sobre sua produção intelectual -, A. Candido hesitou, durante algum tempo, entre pesquisar o processo aculturativo pelo qual passaram os americanos da Vila Americana ou os alemães de Santo Amaro. Finalmente, um convite de Roger Bastide para assistir a uma apresentação sobre "atividades folclóricas" o estimulou a pesquisar o universo da cultura caipira, iniciando estudo sobre poesia popular por meio da análise do cururu, manifestação cultural produzida pelo caipira paulista. Em pouco tempo, porém, o plano original foi deixado de lado, pois "a coerência da investigação levou a alargar pouco a pouco o conhecimento da realidade social em que se inscrevia o cururu", sendo substituído pelo exame da obtenção dos meios de vida (produção, distribuição

15 JACKSON, Luiz Carlos. A tradição esquecida. Belo Horizonte: Editora UFMG, 2002. p. 45. 
e consumo), encarado "não só como tema sociológico, mas também como problema social"16. De modo intermitente, durante os anos de 1947 a 1954, realizou pesquisa de campo na Fazenda Boa Aliança, observando diretamente o cotidiano e a sociabilidade do caipira da região a partir do conceito de bairro rural, entendido como unidade mínima de sociabilidade. Equilibrando-se entre o enfoque antropológico e a perspectiva sociológica na arquitetura teórico-conceitual do trabalho, utilizando autores como Malinowski, Marx, Robert Redfield e Sérgio Buarque de Holanda, A. Candido realizou uma descrição sensível das vicissitudes que os grupos rurais enfrentavam diante do processo de modernização, reivindicando, na parte final, a necessidade de realização da reforma agrária, como medida necessária para evitar a desagregação completa do modo de vida tradicional.

Defendido em 1954 como tese de doutorado em sociologia, o estudo foi alvo de objeções e reparos de membros da banca examinadora, sendo considerado um trabalho de feitio por demais antropológico. No pano de fundo de tais divergências, pode-se entrever uma polarização e uma disputa cada vez maior dentro da FFCL/USP entre modelos de atividades intelectuais qualificadas como culturais e científicas ${ }^{17}$. Não resta dúvida entre os principais estudiosos do assunto de que o principal responsável pelo aprofundamento dessa clivagem e também pela instauração do conhecimento sociológico em bases rigorosas e científicas foi Florestan Fernandes. Diversamente dos colegas de curso reunidos em torno da revista Clima, divididos entre a produção de trabalhos de crítica cultural em jornais e revistas e os encargos de ordem acadêmica, Florestan construiu sua carreira profissional exclusivamente centrada no campo da produção de conhecimento nas ciências sociais, instaurando uma identidade profissional inequívoca ao assumir de modo pleno sua condição de sociólogo.

Proveniente de uma modestíssima família de imigrantes portugueses, Florestan Fernandes nasceu na capital paulista em 1920, exercendo, ao longo da infância e juventude humildes, diversas atividades ocupacionais, enquanto procurava cursar, de maneira intermitente, e às duras penas, os estudos em diferentes escolas públicas da cidade de São

16 CANDIDO, Antonio. Os parceiros do Rio Bonito. São Paulo: Duas Cidades, Editora 34, 2001. p. 25 .

17 Sobre o assunto, ver PONTES, Heloisa. Destinos mistos: os críticos do Grupo Clima em São Paulo. op. cit. 
Paulo. Em 1941, após concluir os estudos secundários no regime de madureza, ingressou no curso de Ciências Sociais da FFLC/USP ${ }^{18}$.

Durante a graduação, concluída entre 1941 e 1944, a despeito das desvantagens educacionais formativas, Florestan destacou-se rapidamente como aluno exemplar e pesquisador promissor, chamando a atenção dos professores graças à rígida disciplina de estudos e à intensa capacidade de trabalho demonstrada. Após formar-se, foi convidado pelo professor Fernando de Azevedo para ocupar a vaga de professor-assistente da cadeira de Sociologia II, dividindo as tarefas com A. Candido. Nos trabalhos de maior envergadura do período inicial de sua trajetória $^{19}$, e, sobretudo, nas polêmicas intelectuais em que se envolveu, já se encontram delineadas as principais características do padrão de investigação científica que o jovem sociólogo defendia e colocava em prática: a) adoção de uma linguagem rigorosa e precisa, permeada de conceitos e termos técnicos, compreensível apenas aos iniciados nos rudimentos das ciências sociais; b) presença indefectível de preâmbulos teórico-metodológicos, com vistas a conferir legitimidade científica e acadêmica às disciplinas que compõem o curso de ciências sociais; c) necessidade de definições e recortes de pesquisa precisos na preocupação de demarcar com rigor fronteiras disciplinares; e) rechaço, no plano da escrita, de qualquer indício estilístico que evocasse o ensaístico, a seu ver comprometido com uma visão estamental de reflexão social.

Encetada a partir do início dos anos 1950, inicialmente por meio da produção científica de Florestan e, logo depois, rotinizada no âmbito da cadeira de Sociologia I - na qual ele substitui, a partir de 1954, o regente Roger Bastide, que retornava para o seu país de origem e o indicara como sucessor -, pela trajetória universitária e intelectual de um grupo coeso de discípulos propensos a perpetuar, em suas linhas gerais,

18 Para uma apreciação mais aprofundada da trajetória acadêmica e intelectual de Florestan Fernandes, conferir os trabalhos de PEIRANO, Mariza G. S. A antropologia de Florestan Fernandes In: . Uma antropologia no plural: três experiências contemporâneas. Brasília, DF: Editora da UnB, 1992. p.51-84; ARRUDA, Maria Arminda do Nascimento. A sociologia no Brasil: Florestan Fernandes e a "Escola Paulista". In: MICELI, Sérgio (Org). História das ciências sociais no Brasil. São Paulo, Editora Sumaré, 1995. v. 2.; PONTES, Heloisa. Destinos mistos: os críticos do Grupo Clima em São Paulo. op. cit., e GARCIA, Sylvia Gemignani. Destino impar. Sobre a formação de Florestan Fernandes. São Paulo: USP, Curso de Pós-graduação em Sociologia/ Editora 34, 2002.

19 Produzidos com vistas à obtenção da titulação acadêmica do autor, são eles: $A$ organização social dos Tupinambás (1947), defendida como dissertação de mestrado na Escola Livre de Sociologia e Política de São Paulo (ELSP); Afunção social da guerra na sociedade Tupinambá (1951), apresentada como tese de doutorado em sociologia na FFCL/ USP; e Ensaio sobre o método de interpretação funcionalista na sociologia (1953), livredocência levada à defesa na cadeira de Sociologia I na mesma instituição. 
o projeto acadêmico de seu mentor, com os quais se formou a chamada "escola paulista de sociologia”, tal padrão de sociológica científica paulatinamente passou a predominar como critério de excelência na avaliação dos trabalhos científicos produzidos dentro da FFCL/USP.

Nesses termos, não é difícil perceber que a pesquisa realizada por A. Candido destoava, em parte, da orientação científica predominante nesse contexto acadêmico específico, seja pelo formato expressivo adotado, seja pelo quadro eclético de referências teóricas oriundo de diferentes áreas disciplinares e seja, ainda, pela presença da proposta política defendida no capítulo conclusivo. Como esclarece Jackson,

Escrito na década de cinquenta, quando a grande preocupação era buscar orientação cada vez mais científica na USP, PRB [Os parceiros do Rio Bonito] afastou-se do "espírito" acadêmico vigente e causou estranhamento. Embora tenha sido bem recebido - o livro teve nove edições entre 1964 e 2001 - foi criticado por misturar esquemas teóricos incompatíveis e também por apresentar linguagem pouco científica. ${ }^{20}$

Não que A. Candido não dispusesse de competência profissional e de sólida formação científica para dar continuidade à trajetória intelectual e acadêmica na área da sociologia. Scholar exemplar, mestre do seu ofício, bastava observar o investimento intelectual que ele realizara nessa área de estudo e de pesquisa ao longo desses anos (artigos importantes, balanços críticos da produção sociológica produzida no país e, sobretudo a redação de $O$ s parceiros do Rio Bonito, referência que se impôs na compreensão no estudo do mundo rural paulista). Ocorre porém que, neste contexto acadêmico em particular, os interesses intelectuais e o estilo científico adotado por A. Candido - a linguagem límpida e despojada do jargão técnico, o ecletismo metodológico, integrando, ainda que de modo seletivo e crítico, esquemas conceituais de autores de procedência diversa - destoava dos anseios de cientificidade que começam a assolar o curso de ciências sociais da FFCL/USP. Como bem o resume Pontes (com a vantagem de explicitar as questões em que estou interessado):

Animada por um "espírito" cientificista, afeita à idéia positivista de pesquisa como sinônimo de análise sistemática da realidade, $\mathrm{e}$ "encarnada" de forma exemplar na figura de Florestan Fernandes, ela [a concepção de sociologia dominante na época] "expulsou"

20 JACKSON, Luiz Carlos. A tradição esquecida. op. cit., p. 62. 
de seus horizontes, quando não dos seus espaços de atuação institucional e de seu universo discursivo, o ensaio e as dimensões estéticas dos fenômenos sociais. A transferência de Gilda de Mello e Souza para a área de estética e a de Florestan para a cadeira de Sociologia I, no ano de 1954, bem como a mudança de Antonio Candido, em 1958, para Assis, após 16 anos de inserção na cadeira de Sociologia II (antes da sua volta em 1960 para a Universidade de São Paulo, como professor de literatura e não mais de sociologia) são indícios extremamente significativos da oposição entre ciência e cultura que se estabelecera, na época, na Faculdade de Filosofia da Universidade de São Paulo. ${ }^{21}$

Não se pode estimar o quanto a recepção da banca desapontou as expectativas de A. Candido quanto ao mérito do trabalho, visto que não há nenhuma declaração explícita sobre o assunto. Não obstante, é de se supor que os anos seguintes à defesa da tese foram bastante difíceis e incertos, nos quais A. Candido encontrou "cada vez menos espaço na cadeira de sociologia para dar continuidade ao seu verdadeiro interesse intelectual: a literatura e a cultura em sentido amplo"22, fato que se observa no escasso número de artigos publicados por ele em 1955 e 1956. Nesse biênio o volume de sua produção intelectual, se comparada aos anos anteriores, declinava sensivelmente. Como exceção, surge Ficção $e$ confissão (1956), volume dedicado ao exame do conjunto da obra literária de Graciliano Ramos. Elaborada a partir da reunião de artigos publicados na grande imprensa, o ensaio acompanha o itinerário da produção literária do escritor alagoano, na ordem em que foi composta, evidenciando a transição dos primeiros romances marcados pela "necessidade de inventar", pela elaboração ficcional, para a emergência nas últimas obras de narrativas baseadas em recordações íntimas e depoimentos pessoais do escritor.

Nesse mesmo ano, começava a circular o Suplemento Literário de O Estado de S. Paulo, publicação semanal dedicada ao debate da produção cultural em geral. Idealizado por A. Candido, autor da concepção e do projeto editorial original, mas dirigido por Décio de Almeida Prado, o Suplemento foi editado a partir de outubro de 1956 até o afastamento de seu editor, ocorrido em meados de 1967. Acolhendo em suas páginas os principais nomes da intelectualidade do país, numa publicação que

21 PONTES, Heloisa. A paixão pela forma. In: MICELI, Sergio e MATTOS, Franklin de (Org.) Gilda, a paixão pela forma. Rio de Janeiro: Ouro sobre Azul, 2007. p. 87.

22 PONTES, Heloisa. Destinos mistos: os críticos do Grupo Clima em São Paulo. op. cit., p.176. 
seguia de perto o "escopo e ideário" da revista Clima, A. Candido retomou aí a publicação de artigos de crítica literária, tornando-se, inicialmente, um dos seus mais assíduos colaboradores. Ao todo, foram mais trinta artigos publicados ao longo dos três primeiros anos de existência do Suplemento.

Mas se a participação no projeto editorial e a colaboração destacada no Suplemento Literário propiciaram-lhe um desafogo sobre as incertezas que rondavam o futuro de sua carreira nessa altura, a decisão de abandonar o cargo de professor-assistente de sociologia permanecia presente. Compelido pelas circunstâncias acadêmicas desfavoráveis e, também, pelo aguilhão de seu temperamento pessoal, A. Candido decidiu declinar do convite recebido para lecionar "Sociologia da Educação", anunciando que deixaria o cargo ocupado na cadeira de Sociologia II para dedicar-se integralmente à crítica literária. Como ele declara:

comuniquei-lhe [a Fernando Azevedo] logo depois da defesa da tese que pretendia largar da sociologia para cuidar apenas de literatura, pois nunca me considerei sociólogo, mas apenas docente de sociologia, o que era outra coisa [...]. Provavelmente por iniciativa de Fernando Azevedo resolveram propor para mim a criação de uma nova cadeira, Sociologia da Educação, matéria que me interessava, mas isso só serviu para apressar minha decisão. Resolvi que o ano de 1956 seria o último como assistente de sociologia e, por isso, me afastei do departamento, passando 1957 em licença-prêmio. Não sabia bem o que iria fazer. Pensei em voltar à crítica literária nos jornais e cheguei a esboçar um plano com Antonio Olavo Pereira, da Editora José Olympio, que sugeriu a distribuição dos rodapés por vários jornais do país, de modo a multiplicar o lucro. Pensei também em associar a isto o ensino de literatura no curso colegial. A única certeza é que não voltaria a ensinar sociologia. ${ }^{23}$

Embora extenso, o trecho acima expressa de modo inequívoco o impasse profissional a que chegara a carreira acadêmica de A. Candido: hesitante com relação ao futuro, não entrevendo alternativas concretas, tampouco enxergando possibilidades de conciliação entre os domínios em que distribuía sua produção intelectual.

23 Idem. Entrevista com Antonio Candido. op. cit., p. 27. 


\section{Atando as pontas da trajetória intelectual}

E não foi necessário voltar. No final de 1957, essa tensão profissional começava a ser dissipada com o convite de Soares Amora para que A. Candido integrasse o grupo de professores responsáveis pela implantação da Faculdade de Filosofia, Ciências e Letras de Assis. Como ele recorda:

Foi quando um amigo meu, José Quirino Ribeiro, a par dos meus problemas, sugeriu a Antonio Soares Amora que me convidasse para ensinar literatura brasileira na Faculdade que este ia dirigir em Assis, uma das três que o Governo do Estado estava criando no interior. Amora me convidou no fim de 1957, eu aceitei e comecei a participar no primeiro semestre de 1958 das sessões de organização da nova Faculdade, no Instituto de Estudos Portugueses. Ela comecaria a funcionar em 1959, mas se instalaria em 58, com alguns professores que dariam cursos preparatórios para o vestibular. ${ }^{24}$

Possibilitado a assumir a vaga oferecida pela posse do título de livre-docente em literatura brasileira, obtido no concurso de 1945, A. Candido não hesitou em afastar-se do cargo e deixar a FFCL/USP, aventurando-se numa nova experiência profissional na qual vislumbrava uma opção promissora para desfazer o impasse a que chegara sua carreira profissional, permitindo selar em definitivo seu compromisso com a crítica literária. Não obstante tenha participado dos trabalhos para a implantação, A. Candido ficou impedido de se dirigir para a Faculdade de Assis durante a primeira metade do ano de 1958 pelo fato de já ter assumido o compromisso de ministrar o curso de Organização Social Brasileira para o segundo ano do curso de ciências sociais na USP25.

À maneira de um ritual de passagem, cuja lógica, desvelada pioneiramente por Arnold Van Gennep ${ }^{26}$, se funda numa sequência tripartite (separação, período transitório de liminaridade e reintegração à comunidade de origem do indivíduo), os dois anos e meio passados em Assis demarcaram uma nítida transição entre as etapas da trajetória acadêmica de A. Candido. Essencial no processo de reconversão simbólica de sua identidade profissional, a passagem por Assis, acima de tudo, garantiu-lhe o respaldo acadêmico necessário para legitimar a condição de professor e pesquisador da área de Letras. E tal fato não passou

24. Idem, ibidem, p. 28.

25 Cf. Idem, ibidem, p. 28.

26 Cf. GENNEP, Arnold Van. Os ritos de passagem. Petrópolis: Editora Vozes, 1978. 
despercebido aos olhos de A. Candido: "foi bom passar dois anos fora da USP. Quando voltei, no começo de 1961, as pessoas já estavam habituadas à minha nova condição"27.

De outro lado, afastada dos grandes centros universitários, a Faculdade de Assis lhe oferecia o recolhimento necessário para aprofundar os estudos. Como ele afirma: "Fiz os estudos e me preparei para os muitos cursos que dei mais tarde na USP. Aprendi técnicas de análise e li muito sobre teoria literária. Foram dois anos e meio de aprendizado integral"28. Favorecido pelo regime de dedicação exclusiva, que permitia aos professores reservar o período da manhã aos estudos, A. Candido encontrou condições favoráveis para colocar em marcha um intenso ritmo de produtividade intelectual:

o resultado de nós passarmos quatro horas toda a manhã lendo, tomando nota, preparando aula, escrevendo, era um rendimento extraordinário. Quatro horas por dia, no fim do ano é uma coisa fantástica! [...] Lá nós éramos como alunos de colégio interno, eram quatro horas de estudo. Depois à tarde a gente dava as aulas e atendia os alunos [...]. ${ }^{29}$

No segundo semestre de 1959, A. Candido inicia sua participação, lecionando, para os alunos ingressantes, Introdução aos Estudos Literários: crítica textual - curso subdividido em dois setores: análise histórica e erudita, a cargo de A. Candido, e iniciação à análise de textos, sob a respon-

27 CANDIDO, Antonio. Os vários mundos de um humanista. [jun.1993]. Entrevistadores: VELHO, Gilberto e LEITE, Yvone. Ciências Hoje, Rio de Janeiro, v. 16, n. 91, p. 28-41, 1993. p. 27. A propósito da ambigüidade profissional que enredava Candido até esta altura, o depoimento de Teresa Vara é bastante significativo. Segundo ela, "não sabia nada sobre o mestre que se dispunha a passar dois anos na Faculdade de Assis, aliás, nós, os seus alunos, não sabíamos nada sobre ele, apenas que terminara uma pesquisa na área de ciências sociais, que só posteriormente viríamos a conhecer quando publicou Os parceiros do Rio Bonito" (VARA, Teresa. Esboço de figurino. In: AGUIAR, Flávio. Antonio Candido: pensamento e militância. São Paulo: Humanitas/Ed. Fundação Perseu Abramo, 1999. p. 229).

28 CANDIDO, Antonio. Entrevista concedida a Décio de Almeida Prado. op. cit., p.11z.

29 Tal experiência beneficiou aos demais professores, a julgar pela qualidade e quantidade de trabalhos publicados na Revista de letras e na Coleção de estudos e ensaios, ambos publicados pela Faculdade de Assis, bem como pela trajetória bem-sucedida da grande maioria. Boa parte do corpo docente inicial recrutado retornou, pouco depois, para a USP, tais como, por exemplo, Erwin Theodor Rosenthal, Julio G. García Morejón, Rolando Morel Pinto. Entre os alunos, aqueles que se destacaram durante a graduação também foram posteriormente aproveitados pela FFCL/USP: Antonio Dimas e Teresa Vara. Cf. OLIVEIRA, Fábio Ruela de. op. cit. 
sabilidade do professor Naief Sáfady ${ }^{30}$. Invertendo a tendência dominante nos cursos de Letras, amparada no estudo da biografia dos autores e na caracterização dos períodos literários, A. Candido priorizou o foco de ensino centrado na primazia da análise textual, prática de ensino inovadora, que será posteriormente seguida em seu retorno à USP como uma das principais diretrizes de ensino do curso de TLLC. A parte oferecida por A. Candido voltou-se para o exame das edições críticas, a partir do estudo dos "diversos tipos de edição que ele trazia para a sala de aula, como a edição príncipe, a fac-similar, a edição diplomática e o exemplar da edição crítica de Rodrigues Lapa, que servia de texto básico para o curso [...]"31. Para apoio didático das discussões realizadas em aula, A. Candido redigiu a apostila "Crítica Textual"32, manual para os alunos enfronhados no paciente trabalho de investigação de edições críticas. Trazendo para o primeiro plano a importância da discussão a respeito dos elementos "que dão à obra individualidade material", a partir da sondagem de "como se faz para decifrar letras, preencher lacunas; dar fidedignidade ao seu texto; averiguar quem a elaborou; mostrar como se leva em conta seu autor; como o ambiente artístico e social influi no seu estilo; como os autores se agrupam em gerações; como as obras possuem características gerais que permitem distingui-las por períodos, etc" ${ }^{\prime 3}$, A. Candido chamou a atenção para uma área de estudo

30 Licenciado em Letras Neolatinas pela USP, Naiéf Sáfady assumiu, a partir de 1954, o cargo de professor assistente da Cadeira de Literatura Portuguesa e tornou-se professor assistente de Literatura Brasileira na Universidade Mackenzie. Em 1959, defendeu tese de doutorado pela USP e, em 1960, conquistou a livre-docência na mesma área de pesquisa. Pode-se ter uma idéia aproximada do conteúdo lecionado por ele pela leitura de Introdução à análise de texto, volume derivado do "esforço didático de orientar os alunos que, desde 1955, têm estado a meu cuidado para iniciação universitária no campo da análise de texto, curso (ou parcela de curso) de que fui encarregado, como assistente, nas Universidades de São Paulo e Mackenzie - e, mais recentemente, no ano de 1959, na Faculdade de Filosofia, Ciências e Letras de Assis, já no setor específico da disciplina de Introdução aos estudos Literários [...]” (SÁFADY, Naief. Introdução à análise de texto. Belo Horizonte: Edições Júpiter, 1972. p. 8). No ano seguinte, “o curso foi atribuído a um titular (Jorge de Sena), já como parte de uma cadeira denominada Teoria da Literatura [...]" (CANDIDO, Antonio. Carta de Antonio Candido. Magma, São Paulo, DTLLC, n. 2, 1995 p.z1). Com a chegada de Sena, Sáfady passa a reger a cadeira de Literatura Portuguesa.$$
\text { Em }
$$
"reprodução, para uso interno de nossa Faculdade, deste texto parcial de um curso introdutório que dei na Faculdade de Assis para o primeiro ano, em 1959. A minha intenção naquela altura era redigir o curso à medida que o fosse ministrando com base em anotações, mas acabei fazendo isso apenas para os tópicos iniciais, que correspondem mais ou menos à terça parte" (CANDIDO, Antonio. Noções de análise histórico - literária. São Paulo: Associação Editorial Humanitas, 2005. p. 7). 
e investigação especializada que até então havia recebido pouca atenção nos currículos dos cursos de Letras. Em 1961, ao assumir o curso de TLLC, esse mesmo conteúdo se tornará matéria do primeiro curso oferecido na Especialização, temática que estimulou a consolidação, no interior do curso de TLLC, de uma prática de pesquisa que viria a ser decisiva na produção crítica de alguns de seus mais destacados discípulos ${ }^{34}$.

No ano seguinte, já na condição de responsável pela cadeira de Literatura Brasileira, A. Candido ofereceu o curso O romance romântico brasileiro: Manuel Antonio de Almeida e José de Alencar. Nele, foi explorada durante o ano todo, em aulas "particulares", com a "única aluna que escolheu literatura brasileira", a leitura e análise dos romances Senhora e Memória de um sargento de milícias (1853). De acordo com Teresa Vara, a aluna em questão ${ }^{35}$, o romance de Manuel Antonio de Almeida teve a composição do entrecho perscrutada de modo exaustivo, na tentativa de "captar a trama, o tecido, a combinação dos fios narrativos, os elementos de ligação de um capítulo para o outro (os elementos conectivos como ele denominava), os cortes e a costura, até chegar bem próximo de entender o princípio estrutural que explicava o romance como um todo"36. Dez anos depois, resultado desse esforço viria a publico com o ensaio Dialética da malandragem $(1970)^{37}$.

Por tudo isso, o ambiente encontrado em Assis representou, no registro de A. Candido, "uma espécie de renascimento intelectual" ${ }^{3}$ :

Nesse período eu estava simplesmente desenvolvendo a arte de ser professor de Literatura. Ali eu me dediquei, sobretudo, a me tornar um bom analista de textos. Eu preparei então uma série

34 Em Assis, Candido identificou o aluno Pedro Caruso, ingressante da segunda turma do curso, como um especialista no assunto (OLIVEIRA, Fábio Ruela de. op. cit., p. 86). Já na USP, pode-se assinalar Walnice Nogueira Galvão e, em especial, Telê Ancona Lopez, ambas responsáveis pelas edições críticas de, respectivamente, Os Sertões (1985) e Macunaíma (1978), como tributárias desse interesse. Principal representante dessa vertente de pesquisa entre os discípulos de Candido, Telê Ancona Lopez elaborou, entre outros, volumes de crônicas, viagens, correspondências e entrevistas de Mário de Andrade.

Após formar-se, Teresa Pires Vara passa a atuar como professora assistente de Literatura Brasileira em Assis. A partir de 1964, retoma o contato com o antigo mestre, inscrevendo-se e passando a frequentar a Especialização do curso de TLLC sob a orientação de Candido. Em 1969, é contratada para compor a equipe de pesquisadores do curso, defendendo, em 1973, tese de doutorado sobre o romance Quincas Borba, de Machado de Assis, publicada anos depois com o título A mascarada sublime (1976).

36 VARA, Teresa. Esboço de figurino. op. cit., p. 230.

37 Publicado no número 8 da Revista do Instituto de Estudos Brasileiros, disponível para consulta on-line no site do Instituto (www.ieb.usp.br).

38 CANDIDO, Antonio. Discurso. In: . Brigada ligeira e outros escritos. op. cit., p. 251. 
de textos de Literatura Brasileira, de prosa e poesia analisados. Quando eu vim para São Paulo eu estava com um material de ensino pronto, foram mais de trinta textos, se eu não me engano, que eu preparei $[\ldots] .{ }^{39}$

Essa retomada produtiva culmina no lançamento da Formação da literatura brasileira (1959). De processo compositivo prolongado, redigida entre 1945 e 1951, retomado em 1955, e submetida a revisões em 1956 (primeiro volume) e 1957 (segundo volume), a obra ${ }^{40}$ talvez seja o mais influente e controvertido dos trabalhos de A. Candido, provocando polêmicas desde o seu surgimento.

Rompendo com a perspectiva tradicional de periodização historiográfica de nossa literatura (seja ela baseada em critérios sócio-políticos ou, entrando em voga à época, estilísticos), A. Candido postula, na introdução do volume, as diretrizes gerais que ancoram o exame dos períodos literários do arcadismo e romantismo. Segundo ele, no processo formativo da literatura brasileira deve-se distinguir analiticamente, de um lado, as "manifestações literárias" (compostas por um conjunto de obras isoladas e desarticuladas entre si, predominantes na fase inicial da produção literária no Brasil, ocorrida entre os séculos XVI e XVIII), e, de outro, "literatura propriamente dita”, definida pela existência de um sistema literário (isto é,

obras ligadas por denominadores comuns, que permitem reconhecer as notas dominantes de uma fase [...]. Entre eles se distinguem: a existência de um conjunto de produtores literários, mais ou menos conscientes de seu papel; um conjunto de receptores, formando os tipos de público, sem os quais a obra não vive; um mecanismo transmissor [de modo geral, uma linguagem, traduzida em estilos] que liga uns aos outros) ${ }^{41}$

39 OLIVEIRA, Fábio Ruela de. op. cit., p. 88. No prefácio de Na sala de aula, volume que enfeixa parte desse material de ensino, Candido comenta: "As versões iniciais destas e muitas outras análises foram redigidas há bastante tempo. Na maioria, entre 1958 e 1960, quando eu ensinava literatura brasileira na Faculdade de Filosofia de Assis, SP" (Idem. Prefacio. In: São Paulo: Editora Ática, 1995. p 6).

40 Guardada na gaveta, a Formação da literatura brasileira foi lançada num momento oportuno e estratégico, já que sua publicação também contribuiu para o processo de legitimação da nova identidade profissional de Candido. Como ele adverte, o livro "dava certo peso" para uma futura contratação no campo das Letras. Cf. CANDIDO, Antonio. Os vários mundos de um humanista. op. cit., p. 27.

4.1 CANDIDO, Antonio. Formação da literatura Brasileira: momentos decisivos. 8. ed. Belo Horizonte: Editora Itatiaia, 1997. p. 24. 
Para A. Candido, é somente quando se consolida o sistema autorobra-público, a seu ver apenas a partir de meados do século XVIII, que se torna possível a "formação da continuidade literária - espécie de transmissão da tocha entre corredores, que assegura no tempo o movimento conjunto, definindo os lineamentos do todo"42.

No intuito de averiguar "quando e como se definiu uma continuidade ininterrupta de obras e autores, cientes quase sempre de integrarem um processo de formação literária"43, a análise se debruça sobre os períodos literários abrangidos pelo arcadismo e romantismo. Radicalmente antitéticos no que se refere a questões de ordem estética (procedimentos literários, tratamentos temáticos, gêneros e técnicas literárias), mas irmanados pelo mesmo desejo de assumir "a atividade literária como parte do esforço de construção do país"44, a consolidação do sistema literário brasileiro culmina na obra de Machado de Assis, escritor que teria conseguido conciliar com maestria os influxos estéticos externos com as soluções expressivas legadas pela produção literária local.

Mais do que revigorar o ritmo e o volume das publicações de A. Candido, o período ofereceu as condições adequadas para o lançamento das bases teórico-metodológicas dafase madura de seu programa de trabalho. Se, como vimos, a expressão mais sofisticada de seu método crítico será fixada, em 1970, com a publicação de Dialética da malandragem, suas premissas básicas foram anunciadas no artigo Estrutura e função do Caramuru. Publicado no segundo número da Revista de letras da Faculdade de Assis, o ensaio apresenta o primeiro esforço analítico representativo do programa crítico concebido por A. Candido nesta terceira fase de suas preocupações teóricas ${ }^{45}$. Pela análise dos princípios estruturais do poema épico Caramuru (1781), de Santa Rita Durão, A. Candido conseguiu compatibilizar análise estética e contexto sócio-histórico, ideologia e representação literária, numa leitura crítica integrativa preocupada em elucidar como "a função histórica de uma obra depende da sua estrutura literária. E que esta repousa sobre a organização formal de certas representações mentais, condicionadas pela sociedade em que a obra foi escrita" ${ }^{46}$.

4,2 Idem, ibidem, p. 24.

43 Idem, ibidem, p. 25.

44. Idem, ibidem, p. 26.

45 Cf. CANDIDO, Antonio. Entrevista In Brigada ligeira e outros escritos. São Paulo: Editora da UNESP, 1992. p.233.

46 CANDIDO, Antonio. Estrutura literária e função histórica. In: Literatura $e$ sociedade. São Paulo: Publifolha, 2000. p. 153. 
Interessado na repercussão alcançada pelo Caramuru meio século depois de sua publicação, quando foi redescoberto pelos primeiros românticos como um dos textos dos fundadores da identidade nacional da literatura brasileira, A. Candido investiga os elementos de ordem estrutural que permitiram que uma obra essencialmente ambígua pudesse ter sido submetida a "um duplo aproveitamento, estético e ideológico" ${ }^{47}$. Segundo A. Candido, embora o Caramuru oscile no plano da composição e da caracterização do personagem principal, de um lado, entre o elogio da colonização portuguesa, a exaltação da paisagem natural e idealização do indígena e, de outro, como prenúncio da consciência nacional, glorificação de segmentos específicos e excepcionais da paisagem e denúncia dos costumes bárbaros dos gentis, tudo culminando na figura ambivalente do personagem principal Diogo Caramuru, cuja imagem vacila entre o colonizador europeu desolado e o branco patriota bem assimilado nos trópicos, a dimensão religiosa, elemento central do poema, confere a unidade que lhe "liga as partes e solve as contradições", permitindo com que ele tenha sido aproveitado ideologicamente anos mais tarde pelos primeiros escritores românticos como epopeia indianista e brasileira.

Da perspectiva destes últimos (influenciada, em parte, pela reputação amealhada pela obra entre escritores franceses, que o valorizaram, traduziram e nele se inspiraram na redação do romance Jakaré-Ouassou, de autoria de Gavet e Boucher) o poema épico adquiriu o status de manifestação nacional por excelência, optando-se, de modo "mais ou menos consciente", por encará-lo como um "poema indianista e nacionalista, precursor e indicador do caminho que então se preconizava"48.

Entre 24 e 30 de julho de 1961, realizou-se em Assis o II Congresso Brasileiro de Crítica e História Literária, evento de especial importância. Sugerida durante o I Congresso de Crítica e Histórias Literária, ocorrido em 1960 na cidade de Recife (PE), após a desistência de Fortaleza (CE), por "impossibilidades de ordem programática", a proposta de realização da segunda edição na "pequena, ainda que progressiva" cidade de Assis, foi aprovada por aclamação pelos participantes da plenária final. Embora já tivesse retornado para a FFCL/USP, para assumir a direção do curso de Teoria Literária e Literatura Comparada, A. Candido participou dos trabalhos da comissão organizadora do evento,

47 Idem, ibidem, p. 155 .

4,8 Idem, ibidem, p. 165.

49 II Congresso Brasileiro de Crítica e História Literária. Assis, 24 - zo de julho de 1961. Anais. São Paulo: Faculdade de Filosofia, Ciências e Letras de Assis, 1963. p. 17. 
encarregando-se, juntamente com o Antonio Soares Amora e Rolando Morel Pinto, da Comissão Coordenadora das Teses e Relatórios.

Durante seis dias de debates científicos, plenárias, mesas-redondas, comissões, resoluções e propostas de trabalho reuniram-se no campus de Assis os principais estudiosos da crítica literária brasileira: "ali, naquela cidadezinha pacata do interior paulista", encontravam-se "os bambas da crítica, figuras do porte de Sérgio Buarque de Holanda, Anatol Rosenfeld, Paulo Emílio Salles Gomes, Décio de Almeida Prado, Wilson Martins, Wilton Cardoso, Joel Pontes, Hélcio Martins, Benedito Nunes, Adolfo Casais Monteiro, Afonso Romano de Sant'Anna, Roberto Schwarz, João Alexandre Barbosa, Décio Pignatari, Augusto de Campos, Haroldo de Campos" ${ }^{\circ 0}$. O que chama a atenção, de saída, é o número impressionante de convidados ilustres, o que certamente se deveu às boas relações de A. Candido com a grande maioria dos críticos citados, que se dispuseram a prestigiar o evento, realizado numa pequena cidade do interior, distante espacialmente da capital, e numa recém-criada faculdade que dispunha, não obstante o nível de excelência dos professores, de instalações acanhadas e nenhuma tradição acadêmica. De outro lado, decerto o congresso também contribuiu para legitimar em definitivo a nova condição profissional de A. Candido perante os pares.

Das intervenções feitas por A. Candido contidas nos Anais do Congresso, destaca-se a participação na Segunda Sessão Plenária, em mesa de trabalho em que o crítico literário português Adolfo Casais Monteiro apresentou o texto $A$ crítica sociológica. De especial importância, o comentário registra, conforme se depreende da transcrição taquigráfica das discussões, a primeira manifestação pública, ainda em forma de esboço, do método crítico que A. Candido vinha amadurecendo após o término da Formação da literatura brasileira.

Ao pedir a palavra, ao final da leitura de Casais Monteiro, A. Candido comenta que:

não poderia deixar de fazer algumas sugestões marginais ao relatório apresentando, mesmo porque sua maneira de encarar a Literatura coincidia perfeitamente com a de A. C. Monteiro, mormente no que dizia respeito ao ponto de vista sociológico no estudo crítico, o qual, ao contrário da opinião comum da crítica, não é um fenômeno obsoleto, pertencente ao passado, mas sim uma tentativa em andamento, 
que já começava a concretizar alguns resultados positivos dentro da orientação sociológica como ficava bem claro na tese em foco. ${ }^{51}$

Para ele, naquele período esboçava-se

um movimento dos mais notáveis na Crítica e no estudo estrutural da obra literária, movimento começado no campo linguístico, com os poetas, e que se vai ampliando na medida em se aproxima da estrutura real da obra literária. Nessa nova posição está presente todo o conjunto da experiência humana, não mais como elemento de valorização, mas como ingrediente que compõe a obra e que a Crítica estuda como elemento presente, como elemento integrante, estrutural da obra literária. ${ }^{52}$

Retomando, anos depois, os comentários emitidos durante o Congresso, o ensaio Crítica e sociologia (1965) apresentava a formulação mais explícita e sistemática da preocupação com a questão da redução estrutural, isto é, "o processo por meio do qual o que era condicionante se torna elemento pertinente" ${ }^{95}$. Representando um dos poucos escritos de natureza teórico-metodológica no conjunto da obra de A. Candido, o ensaio procura dar uma resposta mais sofisticada à questão das análises internas e externas em literatura dentre as alternativas disponíveis de abordagem sociológica, culminando na parte final na formulação de uma proposta que leva em conta os elementos externos como fatores integrantes da estrutura literária: "o externo (no caso, o social) importa, não como causa, nem como significado, mas como elemento que desempenha certo papel na constituição da estrutura, tornando-se, portanto, interno" ${ }^{4}$.

Do ponto de vista profissional, o Congresso de Assis ensejou a ocasião para uma série de contatos e acordos com alguns intelectuais que viriam posteriormente a assumir cargos docentes no curso de TLLC, quando A. Candido preocupou-se "em formar uma equipe, que pudes-

51 II Congresso Brasileiro de Crítica e História Literária. Anais. op. cit., p. 120. Grifo no original.

52 Idem, ibidem, p. 121. Grifos no original.

53 CANDIDO, Antonio. Entrevista. In: Brigada ligeira. São Paulo: Editora da UNESP, 1992. p. 233.

54 Idem. Crítica e sociologia. In: . Literatura e sociedade. op. cit., p. 6; 
se continuar e desenvolver as atividades da disciplina recém-criada" ${ }^{55}$. Dentre eles, destacavam-se Roberto Schwarz e João Alexandre Barbosa.

Filho de imigrantes judeus austríacos que vieram para São Paulo após a ascensão do nazismo, Roberto Schwarz cursou Ciências Sociais na USP entre 1957 e 1960, sendo aluno de A. Candido no terceiro ano da graduação, na disciplina Organização Social do Brasil. Sentindo-se pouco adaptado, no final do curso, ao padrão de trabalho intelectual que então prevalecia em sua área de formação, cujas principais características comentei acima, e já propenso a seguir carreira no campo da crítica literária, com a publicação dos primeiros trabalhos na área ${ }^{56}$, Schwarz decidiu procurar A. Candido durante o II Congresso de Crítica e História Literária. Em suas palavras:

No terceiro ano da faculdade comecei a enxergar o rumo que as ciências sociais tomavam. Estava ficando claro que o bom sociólogo era alguém que faria pesquisa empírica, de preferência quantitativa, com metodologia norte-americana. Eu senti que não era minha vocação. Fui, então, chorar as mágoas com Antonio Candido, que tinha passado para as letras, e naquele momento, estava em Assis. [...] Então fui até lá perguntar a ele o que achava da minha crise, que, mal comparando, já tinha sido a dele. Ele me estimulou e depois me convidou a ser assistente dele, desde que eu fizesse um mestrado em teoria literária e literatura comparada no estrangeiro. ${ }^{57}$

Decidida a questão, por recomendação de A. Candido, já à frente do curso de TLLC, Schwarz obteve, em fins de 1961, uma bolsa de pesquisa para aperfeiçoar os estudos em teoria literária no meio universitário norte-americano, permanecendo na Universidade de Yale, durante o período de um ano e meio, sob a orientação do renomado René Wellek ${ }^{58}$. De volta ao país, no final de 1963, o jovem crítico foi nomeado professorassistente do curso, ficando encarregado das aulas de Introdução aos Estudos Literários.

55 Idem. Memorial apresentado para concurso de professor titular de Teoria Literária e Literatura Comparada na Faculdade de Filosofia, Letras e Ciências Humanas da Universidade de São Paulo em z/7/1974, 1974. p. 21.

56 Sobre o assunto, ver SCHWARZ, Roberto. Entrevista (entrevista concedida a Fernando de Barros Silva). Folha de S.Paulo em o1/o6/97, 1997; Um crítico na periferia do capitalismo. Entrevista concedida a Luiz Henrique Lopes dos Santos e Mariluce Moura, publicada em Pesquisa Fapesp, n. 98, 2004.

57 Idem, ibidem, p.ı.

58 Cf. Idem. Memorial acadêmico apresentado no Departamento de Teoria Literária do Instituto de Estudos Lingüísticos (IEL), Unicamp, 1990. 
Bacharel pela Faculdade de Direito do Recife, João Alexandre Barbosa seguiu carreira na área das Letras, lecionando em "duas faculdades e escrevendo em jornais". Dos primeiros leitores a comentar a Formação da literatura brasileira, João Alexandre Barbosa apresentou em mesa-redonda do Congresso, quando de fato se iniciaram seus contatos pessoais com A. Candido, comunicação sobre a historiografia literária brasileira, ressaltando a contribuição da Formação para o desenvolvimento das novas formas de pesquisa histórico-literária", ao procurar articular uma "investigação sociológica a uma compreensão estilística da Literatura"59.

Ao assumir em 1963 a direção do curso de Teoria Literária na então Universidade do Recife, João Alexandre começou a intensificar sua relação com A. Candido por meio de correspondência epistolar, na qual solicitava sugestões para a criação de uma disciplina nos moldes do curso oferecido por A. Candido na USP ${ }^{60}$. Com o golpe de 1964, decidiu deixar o cargo na capital de Pernambuco após ter por "duas vezes a nossa casa invadida pela polícia, pelo exército”. Na ocasião, procurou por A. Candido "que acenou com a possibilidade de vir para cá (São Paulo)". No entanto, "nesse mesmo ano, o Antonio Candido foi convidado para ir a Paris, mas, através de recomendação e correspondências dele com o escritor Cyro dos Anjos, que era Diretor do Departamento de Letras da Universidade de Brasília, eu fui para lá com minha família no início de 1965”61. Pouco tempo depois, com a invasão da UNB pelos militares, Alexandre Barbosa é demitido conjuntamente com boa parte do quadro docente da recémcriada instituição de ensino, sendo obrigando a retornar ao Recife e reassumir suas atividades profissionais anteriores. Em fins de 1966, entra em contato novamente com Candido - que nessa altura já havia retornado da França -, decidido a vir para São Paulo, fato que se efetiva em 1967, primeiro como bolsista da Fapesp - com a obrigação de ser auxiliar de ensino no curso de TLLC - e, a partir de 1969, integrado definitivamente ao curso, em cujo âmbito defende, em 1970, sob a orientação de Candido, tese de doutorado sobre a obra crítica de José Veríssimo.

Com o II Congresso de Crítica e História Literária encerrava-se em definitivo a participação de A. Candido na Faculdade de Filosofia, Ciências e Letras de Assis. Em 1961, ele já dava início a uma trajetória de intensa atividade intelectual na USP, como principal professor, pesquisador

59 II Congresso Brasileiro de Crítica e História Literária. Anais. op. cit., p. 177.

6 o Cf. CANDIDO, Antonio. Carta de Antonio Candido. Magma, São Paulo, DTLLC, n. 2, 1995 .

61 BARBOSA, João Alexandre. A formação do DTLLC - Depoimento. Magma Revista, São Paulo, n. 2, 1995. p. 26. 
e responsável pelo curso de Teoria Literária e Literatura Comparada ${ }^{62}$, implantando um projeto de ensino e pesquisa bem-sucedido, articulado em vários níveis acadêmicos de atuação: na organização do currículo da graduação e pós-graduação; no recrutamento e contratação, entre alunos e orientandos, de futuros professores; no estímulo à aquisição de acervos intelectuais e pessoais de grandes intelectuais e escritores (incorporando tal espólio ao meio universitário, assim como supervisionando o seu acesso e consulta); na captação de recursos financeiros para pesquisa (através de bolsas de pesquisa da recém-criada Fapesp); na implementação de amplos projetos de pesquisa coletiva, e, sobretudo, na formação e treinamento acadêmico de, pelo menos, três gerações de críticos literários. Nessa altura, já começavam a ficar para trás os percalços de uma trajetória inicialmente indefinida entre o compromisso acadêmico com a sociologia e produção intelectual na área da crítica literária, para cujo desfecho e resolução a passagem por Assis foi fundamental.

62 Sobre o assunto, ver: RAMASSOTE, Rodrigo Martins. Na sala de aula: Antonio Candido e a crítica literária acadêmica (1961-1970). Literatura e sociedade, São Paulo: Departamento de Teoria Literária e Literatura Comparada da Faculdade de Filosofia, Letras e Ciências Humanas da Universidade de São Paulo, n. 12, p. 88-101, 2009. 